\title{
(6) OPEN ACCESS \\ Work characteristics, socioeconomic position and health: a systematic review of mediation and moderation effects in prospective studies
}

\author{
Hanno Hoven, ${ }^{1,2}$ Johannes Siegrist $^{1}$
}

- Additional material is published online only. To view please visit the journal online (http://dx.doi.org/10.1136/ oemed-2012-101331).

${ }^{1}$ Faculty of Medicine, HeinrichHeine-University Düsseldorf, Life-Science Center, Düsseldorf, Germany

${ }^{2}$ Faculty of Medicine, Institute of Medical Sociology, HeinrichHeine-University Düsseldorf, Duesseldorf, Germany

\section{Correspondence to} Hanno Hoven, Faculty of Medicine, Heinrich-HeineUniversity Düsseldorf, LifeScience Center,

Merowingerplatz $1 \mathrm{a}$, Düsseldorf D-40225, Germany; Hanno.hoven@med.uniduesseldorf.de

Received 26 December 2012 Revised 26 March 2013 Accepted 10 May 2013 Published Online First 5 June 2013

To cite: Hoven H, Siegrist J.
Occup Environ Med
2013;70:663-669.

\begin{abstract}
Social inequalities in health persist in modern societies. The contribution of adverse work and employment conditions towards their explanation is analysed by two approaches, mediation and moderation. Yet the relative significance of each approach remains unclear in respective research. We set out to study this question by conducting a systematic literature review. We included all original papers based on prospective observational studies of employed cohorts that were published between January 1980 and October 2012 meeting our search criteria, by using major databases and by observing established quality criteria. 26 reports were included after quality assessment. 17 studies examined the mediation hypothesis and nine studies tested the moderation hypothesis. Moderate support was found for the mediation hypothesis where OR or HR of health according to socioeconomic position (SEP) were reduced in a majority of analyses after introducing work characteristics in multivariate models. Evidence in favour of the moderation hypothesis was found in some studies, demonstrating stronger effects of adverse work on health among people with low SEP. Despite some support in favour of the two hypotheses future research should aim at reducing the heterogeneity in defining and measuring core variables and at applying advanced statistical analyses. Policy recommendations would benefit from a higher degree of consistency of respective research evidence.
\end{abstract}

\section{INTRODUCTION}

There is robust evidence of a social gradient of major chronic diseases and other health measures, based on prospective observational studies of employed populations in a majority of modern societies. ${ }^{1-3}$ The lower people's socioeconomic positions (SEP) are, the higher is their risk of morbidity and impaired health. Work and employment conditions play a prominent role in scientific attempts towards explaining this social gradient, given their primary impact on adult everyday life, its obligations, resources and rewards. ${ }^{4-6}$ Although SEP is often measured by occupational characteristics, such as job status, job classification, or employment grade, this information has limited explanatory power as it does not offer a more refined understanding of the ways in which occupational position affects health. Moreover, as these effects are bidirectional research has to assess the relevance of each one of the two pathways, causation and selection. Recent life course research emphasises a triggering role of adverse early life circumstances, including poor health, on occupational

\section{What this paper adds}

- To what extent adverse working conditions contribute towards explaining social inequalities in health has been analysed by studies testing the mediation and moderation hypotheses.

- So far, the relative significance of each hypothesis remains unclear, and the majority of available evidence was derived from cross-sectional studies.

- Based exclusively on prospective cohort studies, the results of this systematic review provide moderate support of the mediation hypothesis and modest support of the moderation hypothesis.

- Given a high degree of heterogeneity of core measurements analysed in these studies we propose specific recommendations for more standardised procedures in future research.

careers. $^{7}$ Yet several findings from longitudinal studies indicate that the pathway from work to health ('causation') adds more to the explanation of the social gradient than the reverse pathway from health to work ('selection'). ${ }^{8}$

Traditionally, physical stressors and occupational hazards were considered major causes of work-related health risks. Several of these stressors and hazards continue to follow a social gradient in developed western economies, but evidence indicates that they strongly cluster among low skilled occupations and people with atypical or precarious employment. ${ }^{6} 1011$ To date, given profound changes in the nature of employment and work (expansion of service sector, growing impact of information technology, flexibility of employment arrangements), health-adverse work time arrangements and stressful psychosocial work environments are affecting large parts of the workforce. ${ }^{12}$ With the advent of economic globalisation stressful psychosocial work environments became even more important in terms of health-adverse effects. ${ }^{13}$ The experience of work pressure in combination with threats to job stability is no longer confined to low skilled occupational groups, but increasingly affects better trained occupations. ${ }^{14}$ It is therefore important to know more exactly how work characteristics in modern economies affect the health of working people and to what extent these associations explain the social gradient of health. 
Occupational health research has tackled this latter challenge by applying two strategies of analysis: mediation and moderation. The mediation hypothesis claims that the strength of association between SEP and health is abolished or substantially weakened if the effect of work characteristics on health is estimated in multivariate regression models. A respective reduction in effect size is interpreted as a partial explanation of the social gradient of health by the work characteristic under study. ${ }^{15} 16$ Traditionally, in a majority of cases, epidemiological studies tested the mediation hypothesis by applying stepwise multivariate regression analysis. However, pathway analysis or structural equation modelling seem more appropriate statistical approaches as they allow for combined estimation of the direct and indirect effects of SEP and work characteristics on health. ${ }^{17}$

According to the moderation hypothesis the effect of a predicting variable (work characteristic) on a criterion variable (health) varies according to the level of a third variable (SEP). In this case, stronger effects of adversity at work on health are expected among employed people in less privileged as compared to more privileged socioeconomic conditions. To this aim, stratified analyses are performed, and an interaction term (of work and SEP on health) is assessed. Despite the direct policy implications of this latter approach-higher susceptibility to the exposure among people with low SEP points to priorities in administering interventions-the moderation hypothesis has been tested less frequently than the mediation hypothesis in research on work characteristics and social inequalities in health ${ }^{9}$ (see below).

To the best of our knowledge, no systematic review focusing exclusively on prospective observational cohort studies that tested the mediation and moderation hypothesis of the social gradient of health with reference to work characteristics is available so far. In this contribution, we set out to fill this gap. Our main aim was to document whether and to what extent findings from prospective studies lend support to the two hypotheses (mediation and moderation), even given considerable heterogeneity of work-related exposures and health outcomes in these studies. As both hypotheses address potential entry points for preventive activities at work that aim at reducing health inequalities, ${ }^{12}$ it is important to assess the quality of available empirical evidence. This aim to some extent conflicts with another important aim of systematic reviews, and specifically meta-analyses, that is, to provide knowledge based on well comparable measures of specific exposures and specific outcomes. Throughout the paper, this tension will be discussed, and recommendations are proposed on how to strengthen further scientific evidence and its potential policy impact.

\section{METHODS}

The review was performed by observing the criteria defined in the PRISMA statement. ${ }^{18}$ Below we explain eligibility criteria concerning study design, sample and data analysis in more detail.

\section{Study design}

This review is restricted to prospective observational cohort studies as we aim at targeting the best available quality of data with regard to potential causal associations in epidemiological studies. ${ }^{19}$ Therefore we excluded cross-sectional studies. We also excluded longitudinal studies with a follow-up duration less than 1 year as a short time interval confers a high risk of reverse causation. At study entry, participants had to be free from the disease outcome under study, or baseline health measures had to be adjusted for in subsequent analyses. Furthermore, we undertook a quality assessment regarding appropriate handling of adjustment procedures for relevant (eg, sociodemographic) confounders and appropriate statistical methods (eg, test for interaction in moderation analyses). To prevent multiple consideration of the same study in different papers, we selected the paper with highest data quality (eg, validity of outcomes and exposure, duration of longitudinal study and general quality assessment), but we included more than one report from the same study (in the case of the British Whitehall II and the French GAZEL study) if different health outcomes or different work characteristics (eg, different work stress models) were tested.

\section{Study sample}

We included studies of working age populations who were employed at entry. Studies with a sample size of less than 1000 were excluded for reasons of limited statistical power.

\section{Exposures and health outcomes}

Our selection criteria targeted studies with available data on SEP and on distinct health-adverse physical and chemical hazards or psychosocial working conditions. These data had to be assessed at baseline or during follow-up. Furthermore, the studies had to provide data on SEP and on health-adverse working conditions. SEP was measured by occupational position or employment grade in a majority of studies. However, several important investigations used education as a measure of SEP, and some studies applied both indicators. One study only focused on income as an SEP indicator. In view of the importance of each one of these internationally established indicators of $\mathrm{SEP}^{1}$ we decided to include studies that applied at least one of them. Concerning the measures of stressful psychosocial work characteristics we included all available operational approaches as long as at least short versions of psychometrically validated scales or established indicators (eg, job insecurity) were used. With regard to health outcomes all available respective measures were included, whether based on self-report or on more objective information. Yet as common method variance between self-reported exposures and self-reported outcomes cannot be excluded, we gave priority to studies using more objective health measures by classifying these study results at the top in respective tables.

\section{Information sources and data extraction}

Systematic search was undertaken in PubMed and Scopus. The search was based on specified terms (see below), and original papers in peer-reviewed international journals published in English, French or German language between January 1980 and October 2012 were targeted. Conference papers and government-commissioned reports were not considered. Search terms included work environment factors and related health outcomes. In the first stage of the search strategy, based on titles and abstracts, we did not include terms measuring social inequalities, given a lack of consistent documentation of respective terms in abstracts. However, in a second stage, information on SEP was screened by reading all abstracts and full texts of respective articles. Search terms regarding work environment were: physical exposures, toxic exposures, psychosocial working conditions, job demands, job control, social support at work, job strain, effort-reward imbalance, and organisational justice. Search terms for health outcomes were: all-cause mortality, morbidity, cardiovascular disease, ischaemic heart disease, diabetes, metabolic diseases, myocardial, ischaemic, diabetes, workrelated injuries, occupational accidents, suicide, musculoskeletal 
Figure 1 Selection process for identification of studies.

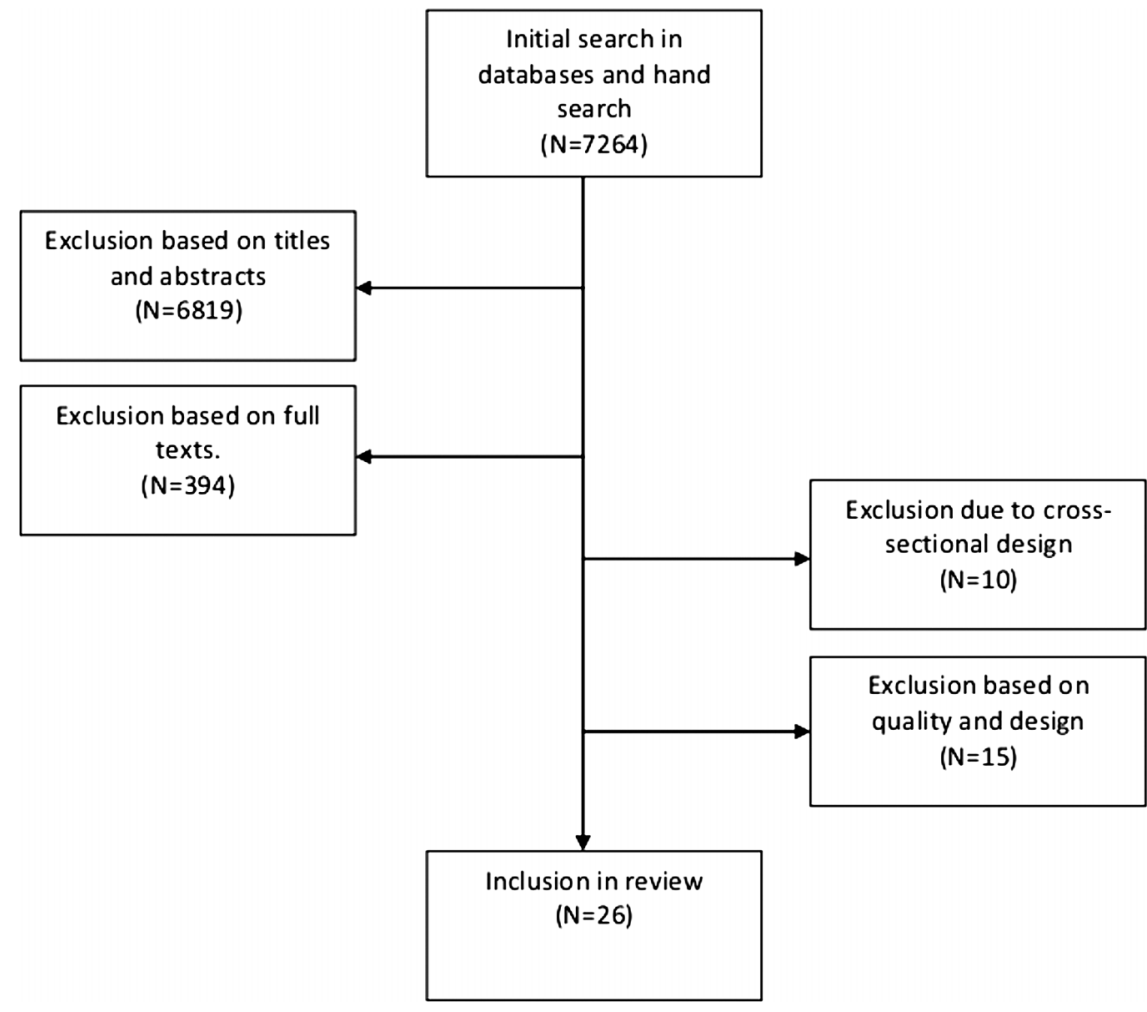

disorders, health functioning, disability, disability pension, mental health, depression, and self-rated health. In addition to the systematic review procedure hand search research was conducted by contacting scientific teams involved in current work on social inequalities, work and health. This was done in order to include most updated evidence.

In a first stage, all records were judged by the first author on the basis of titles and abstracts. In difficult cases, full texts were consulted, and ambiguities were discussed between the authors (see flowchart figure 1). In a second stage both authors examined the remaining papers independently and searched for studies analysing the mediation or moderation hypothesis. To this aim, full texts were available, and the two independent ratings were compared. The few discordant cases were resolved by in-depth discussion. Data were extracted in a standardised format, according to categories indicated in supplementary tables S1 and S2 (available online only).

In most studies, mediation effects were evaluated using multivariate regression analysis with stepwise adjustments for confounders and mediators. In this procedure, the contribution of the mediating variable(s) to the explanation of social inequalities in health was estimated by the change in OR or HR after inclusion of the variable(s) in the model. The respective formula was $100 \times\left(\mathrm{OR}_{\text {extended model }}-\mathrm{OR}_{\text {Model } 1}\right) /\left(\mathrm{OR}_{\text {Model } 1}-1\right) .{ }^{20}$ In case of reduction of $\mathrm{OR}$ or $\mathrm{HR}$ in the extended compared to the previous model, the percentage gives an estimate of how much the mediating variable(s) account for the social gradient of the health indicator under study. This percentage is interpreted as partial mediation contributing to the explanation of social inequalities in health. One study only applied path analysis to test the mediation hypothesis ${ }^{21}$ estimating the direct and indirect (work-related) effects of SEP on health. The moderation hypothesis was evaluated by stratified analyses in which the effect size on health was calculated for different SEP groups, assuming higher effect sizes among lower SEP groups.

\section{RESULTS}

Our search strategy provided 7264 initial records screened by the first author. Six thousand eight hundred and nineteen titles were excluded based on title and abstract content. The remaining 443 records were checked more precisely in full texts and were additionally evaluated according to whether relevant information (on SEP, on test of mediation or moderator hypothesis) was available. Given the restrictive selection criteria several interesting studies had to be excluded as they were based on a cross-sectional design $(n=10)$, or did not meet additional quality or design criteria $(n=15)$. Therefore, as demonstrated in figure 1, studies from 26 reports finally fulfilled all selection criteria to a sufficient extent. As one report contained results from two studies, 17 prospective studies tested the mediation hypothesis (see supplementary table S1, available online only), and nine prospective studies tested the moderation hypothesis (see supplementary table S2, available online only). Overall, it is apparent that relatively few papers investigated these mediation or moderation effects in the frame of cohort studies, whereas separate effects of socioeconomic or of work-related factors on health have been explored abundantly.

\section{Mediation}

In 13 studies, the most widely used model of a health-adverse psychosocial work environment, demand-control (or its single dimensions), was studied as the mediating construct. ${ }^{22}$ Two studies tested the effort-reward imbalance model ${ }^{23}$ in addition to the demand-control model, and one study analysed the effort-reward imbalance model exclusively. One study tested a job-exposure matrix considering psychosocial working conditions. ${ }^{24}$ Seven studies analysed physical demands or biomechanical strains in addition to the demand-control model, whereas one study was restricted to physical exposures and chemical substances. ${ }^{25}$ The latter study was the only one that included a 
large number of European countries, while the remaining studies were conducted in single countries of northern, southern or western Europe or Canada.

Health outcomes in those studies can be divided into more objective and more subjective measures. The former include cardiovascular diseases, lung cancer, disability pension and sickness absence, whereas the latter mainly concern self-rated health, depression, low back pain, or functional limitations. In a majority of studies SEP was assessed by occupational category (eg, ISCO-88) or employment grade (12 studies). ${ }^{20} 21 \quad 24 \quad 26-34$ In order to synthesise the current knowledge we included studies using education (two studies), ${ }^{16}{ }^{25}$ income (one study), ${ }^{35}$ or the combination of employment grade and education (one study). ${ }^{36}$ In addition, one study tested occupation and education as alternative indicators. ${ }^{37}$ As mentioned, one study only applied pathway analysis, while the majority of reports tested the mediation hypothesis using stepwise regression analysis. It should be noted that four out of the 16 studies were based on data from the British Whitehall II study, and two reports were based on the French GAZEL cohort.

All studies report a social gradient of health. In addition, poor working conditions are more prevalent among employed people with low skill level or low occupational standing. As evident from supplementary table S1 (available online only) OR or HR of low versus high SEP are generally higher in reports that used self-reported health outcomes compared to those using medical diagnoses (except Toivanan and Hemström). ${ }^{35}$ The crucial information about the mediation hypothesis is provided by comparing the percentage reduction in OR or HR between the first step of a regression model (SEP and health) and the second step of the model, adjusting additionally for work characteristics. In a majority of cases, a percentage reduction between the two OR or HR is observed, as assumed by the mediation hypothesis. However, the amount of percentage reduction, that is, the strength of a mediation effect, varies considerably. This variation is of interest in three respects, first with regard to the applied SEP indicator, second with regard to objective versus subjective health indicators, and third with respect to the mediating construct, that is, work characteristics, although these conditions overlap within the studies.

In general, mediation effects are more consistently observed in studies based on employment grade as a measure of social inequality, compared to those using alternative SEP indicators. This conclusion is supported by the study that provides an alternative test of both SEP indicators and observes stronger percentage reduction in the case of employment grade. ${ }^{36}$

Concerning a comparison of mediation effects between studies using more objective versus subjective health outcomes an interesting finding becomes obvious. With two exceptions, mediation effects tend to be somewhat stronger if objective health outcomes are analysed. One of these exceptions relates to depression in which a combination of both psychosocial work stress models contributes towards explaining the social gradient quite remarkably, especially among men. ${ }^{32}$ The other exception is observed in a study focusing on biomechanical stressors with regard to low back pain. ${ }^{33}$ This latter finding is best understood in terms of the third source of variation, work characteristics. It appears that studies that combine psychosocial and physical work stressors achieve relatively stronger mediation effects although two studies only analysed these two effects separately. ${ }^{28} 33$ As the demand-control model was applied in a majority of studies no comparison of mediation effects with alternative psychosocial exposures was possible. Some study results confirm that this model, or its single components, makes a distinct contribution towards explaining the social gradient of health.

\section{Moderation}

Five of the nine studies included in this part of the review used the demand-control model, $938-41$ two studies were based on the effort-reward imbalance model, ${ }^{42}{ }^{43}$ one study analysed several aspects of work-related social support, ${ }^{44}$ and one study applied a job-exposure matrix of different occupational solvents. ${ }^{45}$ Given the relatively small number of studies, a further differentiation according to SEP indicators or health outcomes is not feasible. It should also be kept in mind that any generalisation of findings related to the moderation hypothesis is limited by the fact that three out of nine reports are based on the same cohort, the British Whitehall II study. Although they address different health outcomes and different time frames within the longitudinal design there is a clear risk of over-reporting.

According to the moderation hypothesis stronger effects of work characteristics on health outcomes are expected in low SEP as compared to high SEP groups. This hypothesis finds empirical support in four studies. Two of them tested the effort-reward imbalance model, ${ }^{42}{ }^{43}$ one the demand-control model, ${ }^{40}$ and one the chemical exposure of different solvents. ${ }^{45}$ A fifth investigation reports that a mitigating effect of a favourable psychosocial work environment (social support and job security) on the amount of experienced distress is confined to the subgroup with low socioeconomic standing, while it is absent among higher SEP groups. ${ }^{9}$ Three of the four remaining studies observed higher OR or HR among more privileged as compared to less privileged occupational groups, thus contradicting the general hypothesis. ${ }^{38} 3944$ However, in one of those studies this only holds true for men, ${ }^{38}$ and in another study this effect is restricted to one out of three work characteristics entering statistical analysis ${ }^{44}$ (see supplementary table S2, available online only).

In view of the small number of studies and the heterogeneity of relevant measures it is difficult to find a consistent pattern of results with regard to the moderation hypothesis. Yet slightly more results are in favour of the hypothesis, whereas negative findings from at least three studies challenge this assumption.

\section{DISCUSSION}

To our knowledge, this is the first systematic review of available cohort studies testing the mediation or the moderation hypothesis of adverse working conditions in the context of social inequalities in health. Based on an analysis of 27 prospective investigations we found some empirical support in favour of either assumption. However, given the heterogeneity of measures applied in these studies the degree of consistency of findings was clearly restricted. The decision on including reports using different indicators (specifically of SEP and of health outcomes) was based on the premise that these two hypotheses offer important entry points of preventive activities at work with potential benefit for reducing health inequalities and, thus, that systematic knowledge on a broad spectrum of current evidence would instruct these activities.

Several findings deserve attention. Concerning the mediation hypothesis, first, a majority of studies support the notion that adverse working conditions to some extent mediate the association of SEP with health. Respective percentage reductions in OR were sometimes modest, but in a few instances rather substantial, in particular if physical stressors were included or combined with psychosocial stressors. Second, studies that 
used occupational categories or employment grades as indicators of SEP provided more robust findings than those using education or income as indicators. Third, with two noticeable exceptions, studies based on objective health measures demonstrated somewhat stronger mediation effects than studies based on self-reported health measures. Concerning the moderation hypothesis, results are less consistent as five out of nine studies only support the hypothesis of stronger effects among lower versus higher socioeconomic groups. Three of those studies used the effort-reward imbalance model or the demand-control model, and one applied a job exposure matrix of chemical solvents. On balance, in view of moderate support of the mediation hypothesis and modest support of the moderation hypothesis, it seems appropriate to draw preliminary rather than firm conclusions from the available evidence, given the relative paucity of studies, the heterogeneity of definition criteria and measures of core variables, and the limitations of applied statistical analyses.

There is a remarkable contrast of the consistency and strength of reported effects between the prospective investigations analysed in this contribution and the cross-sectional studies that tested the two hypotheses so far. In this latter case, a rather high degree of consistency of findings was observed, supporting either hypothesis (for review). ${ }^{5} 69374647$ It is unclear to what extent this discrepancy in the consistency of results according to study design is due to methodological problems (eg, higher risk of reporting bias or common method variance in cross-sectional studies) or to different quality of studies (less heterogeneity of concepts and measures in cross-sectional studies, in combination with more systematic hypothesis testing). In view of the relevant contribution of employment and working conditions to social inequalities in health ${ }^{48}$ there is an urgent need for further clarifying this divergent trend.

Whereas prospective observational cohort studies represent the gold standard in this area of research, cross-sectional investigations may be in a better position to contribute to conceptual and methodological innovations, given a shorter time frame of overall research investment. For instance, one recent important cross-sectional study extended the frame of analysis by testing the contribution of material and psychosocial factors in occupational life and in additional life domains, thus quantifying their respective contribution towards explaining social inequalities in health. ${ }^{46}$ Moreover, that study included data from 28 European countries, thus providing opportunities of testing differential associations with regard to distinct national social and labour policies (see below).

This systematic review has several limitations. We restricted the search strategy in terms of type of publication (original research articles), language (English, French, German), number of databases consulted (PubMed, Scopus), and choice of search terms. Therefore, we cannot exclude the possibility that some studies bypassed our review. Second, it is entirely possible that due to publication bias studies are overrepresented that reported positive findings. Third, given more sophisticated statistical approaches towards testing the mediation hypothesis, ${ }^{17}$ the majority of studies on which this review is based applied the conventional approach of stepwise regression modelling, which may not provide definite evidence on true mediation effects. Finally, as mentioned, given the heterogeneity of measures across studies, a meta-analysis comparing effect strengths of different study findings was not feasible. This fact restricts the quality of this review, which nevertheless classifies and quantifies available data. ${ }^{49}$

In view of a high amount of heterogeneity concerning core measures applied in the cohort studies and in view of potential advances of more recently developed statistical approaches, it seems timely to call for a higher degree of standardisation and methodological sophistication in future research in this field. In particular, the following criteria might be observed in designing and conducting respective empirical studies.

First, studies should test an explicit theoretically justified hypothesis, rather than exploring what variables may produce statistically significant results. This requires an a priori definition of the core variables entering the analysis of mediation or moderation hypotheses. Second, given the paucity of studies measuring physical and chemical hazards at work, and given the fact that the effects of these exposures were generally strong, there is an urgent need to analyse the combined and separate effects of physical/chemical and psychosocial work characteristics in future interdisciplinary research. Moreover, concerning a health-adverse psychosocial work environment, appropriate tests of respective theoretical models based on psychometrically validated scales should be performed. Along these lines one can argue that respective analyses may even be broadened by including distinct extra-work conditions (as exemplified in one recent study). ${ }^{46}$ Third, with regard to health outcomes, more emphasis could be put on objective outcomes of functioning, morbidity and mortality, thus improving criterion validity. As mentioned, in this review the effect sizes of studies analysing objective health indicators tended to be stronger than those based on selfreported health outcomes. Fourth, while the generation of cumulative knowledge based on established theoretical models, such as the demand-control or the effort-reward imbalance model, is an important scientific goal, these models may need some extension or modification in order to capture more recent trends of health-adverse work and employment appropriately (eg, atypical work, contract work, self-employment; see Clougherty et al). ${ }^{6}$ There is a danger that results from cohort studies (which are predominantly conducted in large companies) are biased by overemphasising those stable work and employment conditions that are more prevalent in large organisations, thereby disregarding the health burden of unstable, precarious work. Fifth, study designs and statistical analyses should take account of the complexity and dynamics of work life in current societies. Among others, structural equation modelling, path analysis and multilevel analysis offer opportunities for respective extensions. Event history methods and multiple longitudinal exposure assessments are desirable, when feasible. The same holds true for the inclusion of contextual measures of workplaces, departments, firms and organisational environments. Finally, in times of economic globalisation, comparative research on the role of work and employment conditions in explaining health inequalities between countries is considered a high priority. With a few exceptions study findings so far are restricted to economically developed countries, mostly in northern or western Europe. Therefore, it will be important to analyse the two hypotheses in non-western countries and in rapidly developing societies. Preliminary results from internationally comparative studies testing the demand-control and/ or the effort-reward imbalance model of adverse work with regard to health indicate that its main results can be replicated in eastern European countries, ${ }^{50} 51$ in rapidly developing countries (for China see Li et $a l^{52}$ and $\mathrm{Xu}$ et al), ${ }^{53}$ and in countries with markedly different cultures (for Japan see Tsutsumi et al $l^{40}$ and Siegrist et al). ${ }^{54}$ Moreover, cross-country analyses provide an opportunity of testing the impact of distinct national labour and social policies on the quality of work and its effects on workers' health. ${ }^{55} 56$ 
In conclusion, the current state of research, as reflected by findings from prospective observational cohort studies, provides some support in favour of the mediation and moderation hypotheses in analysing associations of work characteristics and SEP with health. Given a high degree of heterogeneity of concepts, measurements and methods of data analysis, more standardised research procedures are needed. To this end, several propositions for the generation of improved knowledge were made. It is hoped that, as a result, improved scientific evidence will be available to instruct work and employment-related policies that aim at reducing social inequalities in health.

Acknowledgements The authors are grateful for constructive comments on an earlier version of the manuscript given by the following members of the DRIVERS consortium: Peter Goldblatt, Hynek Pikhart and Demetris Pillas, UCL London; Olle Lundberg, Stockholm University; and Claudia Marinetti and Linden Farrer, EuroHealthNet, Brussels.

Funding This study was supported by grant agreement HEALTH-F3-2011-278350 (DRIVERS) of the European Commission. JS was supported by a special senior professorship grant by the Faculty of Medicine, Heinrich Heine University of Duesseldorf.

\section{Competing interests None.}

Provenance and peer review Not commissioned; externally peer reviewed.

Open Access This is an Open Access article distributed in accordance with the Creative Commons Attribution Non Commercial (CC BY-NC 3.0) license, which permits others to distribute, remix, adapt, build upon this work non-commercially, and license their derivative works on different terms, provided the original work is properly cited and the use is non-commercial. See: http://creativecommons.org/ licenses/by-nc/3.0/

\section{REFERENCES}

1 Lynch J, Kaplan G. Socioeconomic Position. In: Berkman LF, Kawachi I, eds. Social epidemiology. Oxford: Oxford University Press, 2000:13-35.

2 Marmot M. The status syndrome: how social standing affects our health and longevity. New York: Owl Books, 2004.

3 Mackenbach JP, Stirbu I, Roskam AR, et al. Socioeconomic inequalities in health in 22 European countries. N Engl J Med 2008;358:2468-81.

4 Marmot M, Theorell T. Social class and cardiovascular disease: the contribution of work. Int J Health Serv 1988;18:659-74.

5 Siegrist J, Theorell T. Socio-economic position and health: the role of work and employment. In: Siegrist J, Marmot M, eds. Social inequalities in health: new evidence and policy implications. Oxford: Oxford University Press, 2006:73-100.

6 Clougherty JE, Souza K, Cullen MR. Work and its role in shaping the social gradient in health. Ann NY Acad Sci 2010;1186:102-24.

7 Kuh D, Ben Shlomo Y. A life course approach to chronic disease epidemiology. Oxford: Oxford University Press, 2004

8 Chandola T, Bartley M, Sacker A, et al. Health selection in the Whitehall II study, UK. Soc Sci Med 2003;56:2059-72.

9 Ibrahim S, Smith P, Muntaner C. A multi-group cross-lagged analyses of work stressors and health using Canadian national sample. Soc Sci Med 2009;68:49-59.

10 Benach J, Muntaner C, Solar O, et al. Employment, work, and health inequalities: a global perspective. Geneva: WHO, 2007

11 Eurofound. Fifth European working conditions survey. Luxembourg: Publications Office of the European Union, 2012.

12 Schnall P, Dobson M, Rosskam E, eds. Unhealthy work: causes, consequences, cures. New York: Baywood, 2009.

13 Tausig M, Fenwick R. Work and mental health in social context. New York: Springer, 2011.

14 Cooper CL, Pandey A, Quick JC, eds. Downsizing. Cambridge: Cambridge University Press, 2012.

15 Baron RM, Kenny DA. The moderator-mediator variable distinction in social psychological research: conceptual, strategic, and statistical considerations. J Pers Soc Psychol 1986:51:1173-82

16 Hagen $\mathrm{KB}$, Tambs K, Bjerkedal T. What mediates the inverse association between education and occupational disability from back pain?-A prospective cohort study from the Nord-Trøndelag health study in Norway. Soc Sci Med 2006;63:1267-75.

17 MacKinnon DP, Krull JL, Lockwood CM. Equivalence of the mediation, confounding and suppression effect. Prev Sci 2000;1:173-81.

18 Moher D, Liberati A, Tetzlaff J, et al. Preferred reporting items for systematic reviews and meta-analyses: the PRISMA statement. J Clin Epidemiol 2009;62:1006-12.

19 Rothman KJ, Greenland S, Lash TL. Modern epidemiology. Philadelphia: Wolters Kulwer, 2008.
20 Borg V, Kristensen TS. Social class and self-rated health: can the gradient be explained by differences in life style or work environment? Soc Sci Med 2000;51:1019-30.

21 Chandola T, Siegrist J, Marmot M. Do changes in effort-reward imbalance at work contribute to an explanation of the social gradient in angina? Occup Environ Med 2005;62:223-30

22 Karasek R, Theorell T. Healthy work. Stress, productivity, and the reconstruction of working life. New York: Basic Books, 1990.

23 Siegrist J. Adverse health effects of high-effort/low-reward conditions. J Occup Health Psychol 1996;1:27-41.

24 Andersen I, Burr H, Kristensen TS, et al. Do factors in the psychosocial work environment mediate the effect of socioeconomic position on the risk of myocardial infarction? Study from the Copenhagen Centre for Prospective Population Studies. Occup Environ Med 2004:61:886-92.

25 Menvielle $\mathrm{G}$, Boshuizen $\mathrm{H}$, Kunst AE, et al. Occupational exposures contribute to educational inequalities in lung cancer incidence among men: evidence from the EPIC prospective cohort study. Int I Cancer 2010;126:1928-35.

26 Marmot MG, Bosma $\mathrm{H}$, Hemingway $\mathrm{H}$, et al. Contribution of job control and other risk factors to social variations in coronary heart disease incidence. Lancet 1997;350:235-9

27 Melchior M, Krieger N, Kawachi I, et al. Work factors and occupational class disparities in sickness absence: findings from the GAZEL cohort study. Am J Public Health 2005;95:1206-12.

28 Laaksonen M, Piha K, Rahkonen $\mathrm{O}$, et al. Explaining occupational class differences in sickness absence: results from middle-aged municipal employees. J Epidemiol Community Health 2010;64:802-7.

29 Ferrario MM, Veronesi $G$, Chambless $L E$, et al. The contribution of major risk factors and job strain to occupational class differences in coronary heart disease incidence: the MONICA Brianza and PAMELA population-based cohorts. Occup Environ Med 2011:68:717-22.

30 Ferrie JE, Shipley MJ, Stansfeld SA, et al. Future uncertainty and socioeconomic inequalities in health: the Whitehall II study. Soc Sci Med 2003;57:637-46.

31 Mustard CA, Vermeulen M, Lavis JN. Is position in the occupational hierarchy a determinant of decline in perceived health status? Soc Sci Med 2003;57: 2291-303.

32 Stansfeld SA, Head J, Fuhrer R, et al. Social inequalities in depressive symptoms and physical functioning in the Whitehall II study: exploring a common cause explanation. J Epidemiol Community Health 2003;57:361-7.

33 Plouvier S, Leclerc A, Chastang J, et al. Socioeconomic position and low-back painthe role of biomechanical strains and psychosocial work factors in the GAZEL cohort. Scand I Work Environ Health 2009:35:429-36.

34 Pietiläinen $\mathrm{O}$, Laaksonen $\mathrm{M}$, Pitkäniemi J, et al. Changes of occupational class differences in physical functioning: a panel study among employees (2000-2007). J Epidemiol Community Health 2012;66:265-70.

35 Toivanen $\mathrm{S}$, Hemström $\mathrm{O}$. Income differences in cardiovascular disease: is the contribution from work similar in prevalence versus mortality outcomes? Int I Behav Med 2006;13:89-100.

36 Haukenes I, Mykletun A, Knudsen AK, et al. Disability pension by occupational class - the impact of work-related factors: the Hordaland Health Study Cohort. BMC Public Health 2011;11:406.

37 Huisman $\mathrm{M}$, van Lenthe $\mathrm{F}$, Avendano $\mathrm{M}$, et al. The contribution of job characteristics to socioeconomic inequalities in incidence of myocardial infarction. Soc Sci Med 2008;66:2240-52.

38 Hemingway H, Shipley MJ, Stansfeld S, et al. Sickness absence from back pain, psychosocial work characteristics and employment grade among office workers. Scand J Work Environ Health 1997:23:121-9.

39 Kuper $\mathrm{H}$, Marmot M. Job strain, job demands, decision latitude, and risk of coronary heart disease within the Whitehall II study. J Epidemiol Community Health 2003;57:147-53.

40 Tsutsumi A, Kayaba K, Ishikawa S. Impact of occupational stress on stroke across occupational classes and genders. Soc Sci Med 2011;72:1652-8.

41 von, Bonsdorff, Seitsamo MBJ, et al. Job strain among blue-collar and white-collar employees as a determinant of total mortality: a 28-year population-based follow-up. BMJ Open 2012 Mar 15;2(2):e000860. doi:10.1136/bmjopen-2012-000860

42 Kuper $\mathrm{H}$, Singh-Manoux A, Siegrist J, et al. When reciprocity fails: effort-reward imbalance in relation to coronary heart disease and health functioning within the Whitehall II study. Occup Environ Med 2002;59:777-84.

43 Rugulies R, Aust B, Madsen IEH, et al. Adverse psychosocial working conditions and risk of severe depressive symptoms. Do effects differ by occupational grade? Eur J Publ Health 2012. doi:10.1093/eurpub/cks071

44 Väänänen A, Pahkin K, Kalimo R, et al. Maintenance of subjective health during a merger: the role of experienced change and pre-merger social support at work in white- and blue-collar workers. Soc Sci Med 2004;58:1903-15.

45 Sabbath EL, Glymour MM, Berr C, et al. Occupational solvent exposure and cognition. Does the association vary by level of occupation? Neurology 2012;78:1754-60.

46 Aldabe B, Anderson R, Lyly-Yrjänäinen $\mathrm{M}$, et al. Contribution of material, occupational, and psychosocial factors in the explanation of social inequalities in 
health in 28 countries in Europe. J Epidemiol Community Health 2011;65: 1123-31.

47 Lundberg 0. Causal explanations for class inequality in health-an empirical analysis. Soc Sci Med 1991;32:385-93.

48 Marmot M, Allen J, Bell R, et al. WHO European review of social determinants of health and the health divide. Lancet 2012;380:1011-29.

49 Verbeek J, Ruotsalainen J, Hoving JL. Synthesizing study results in a systematic review. Scand J Work Environ Health 2012;38:282-90.

50 Bobak M, Hertzman C, Skodova Z, et al. Association between psychosocial factors at work and nonfatal myocardial infarction in a population-based case-control study in Czech men. Epidemiology 1988;9:43-7.

51 Pikhart $\mathrm{H}$, Bobak M, Pajak A, et al. Psychosocial factors at work and depression in three countries of Central and Eastern Europe. Soc Sci Med 2004;58:1475-82.
52 Li J, Yang W, Cho S. Gender differences in job strain, effort-reward imbalance, and health functioning among Chinese physicians. Soc Sci Med 2006;62:1066-77.

53 Xu W, Zhao Y, Guo L, et al. Job stress and coronary heart disease: a case-contro study using a Chinese population. J Occup Health 2009;51:107-13.

54 Siegrist J, Lunau $T$, Wahrendorf $M$, et al. Depressive symptoms and psychosocial stress at work among older employees in three continents. Glob Health 2012;8:27.

55 Eikemo TA, Bambra C, Judge $K$, et al. Welfare state regimes and differences in self-perceived health in Europe: a multilevel analysis. Soc Sci Med 2008;66:2281-95.

56 Dragano N, Siegrist J, Wahrendorf M. Welfare regimes, labour policies and unhealthy psychosocial working conditions: a comparative study with 9917 older employees from 12 European countries. J Epidemiol Community Health 2011;65:793-9. 